\title{
Monitoring communication with patients: analyzing judgments of satisfaction (JOS)
}

Citation for published version (APA):

Wagner-Menghin, M., de Bruin, A., \& van Merrienboer, J. J. G. (2016). Monitoring communication with patients: analyzing judgments of satisfaction (JOS). Advances in Health Sciences Education, 21(3), 523540. https://doi.org/10.1007/s10459-015-9642-9

Document status and date:

Published: 01/08/2016

DOI:

10.1007/s10459-015-9642-9

Document Version:

Publisher's PDF, also known as Version of record

Document license:

Taverne

Please check the document version of this publication:

- A submitted manuscript is the version of the article upon submission and before peer-review. There can be important differences between the submitted version and the official published version of record.

People interested in the research are advised to contact the author for the final version of the publication, or visit the DOI to the publisher's website.

- The final author version and the galley proof are versions of the publication after peer review.

- The final published version features the final layout of the paper including the volume, issue and page numbers.

Link to publication

\footnotetext{
General rights rights.

- You may freely distribute the URL identifying the publication in the public portal. please follow below link for the End User Agreement:

www.umlib.nl/taverne-license

Take down policy

If you believe that this document breaches copyright please contact us at:

repository@maastrichtuniversity.nl

providing details and we will investigate your claim.
}

Copyright and moral rights for the publications made accessible in the public portal are retained by the authors and/or other copyright owners and it is a condition of accessing publications that users recognise and abide by the legal requirements associated with these

- Users may download and print one copy of any publication from the public portal for the purpose of private study or research.

- You may not further distribute the material or use it for any profit-making activity or commercial gain

If the publication is distributed under the terms of Article $25 \mathrm{fa}$ of the Dutch Copyright Act, indicated by the "Taverne" license above, 


\title{
Monitoring communication with patients: analyzing judgments of satisfaction (JOS)
}

\author{
Michaela Wagner-Menghin ${ }^{1}$ (D) Anique de Bruin² \\ Jeroen J. G. van Merriënboer ${ }^{2}$
}

Received: 2 December 2014/ Accepted: 26 September 2015/Published online: 6 October 2015

(C) Springer Science+Business Media Dordrecht 2015

\begin{abstract}
Medical students struggle to put into practice communication skills learned in medical school. In order to improve our instructional designs, better insight into the cause of this lack of transfer is foundational. We therefore explored students' cognitions by soliciting self-evaluations of their history-taking skills, coined 'judgments of satisfaction (JOSs)'. Our cognitive-psychological approach was guided by Koriat's cue-utilization framework (J Exp Psychol Gen 126:349-370. doi:10.1037/0096-3445.126.4.349, 1997) which rests on the assumption that internal and external cues inform learners' metacognitive judgments, which, in turn, steer their actions. Judgments based on unsuitable cues will cause ineffective behavior. Consequently, students are unable to adequately master these skills or properly apply them in similar situations. For the analysis, we had 524 medical undergraduates select scenes they were satisfied or dissatisfied with from their video-recorded simulated-patient encounters and explain why. Twenty transcripts were sampled for directed content analysis. We found that approximately one-third of students' judgments focused on content (JOS-type-a); about half on the quality of the communication skills (JOS-type-b); and about ten percent targeted the appropriateness of the skills harnessed (JOS-type-c). This lack of reflection on appropriateness may explain why students experience problems adapting to new situations. It was primarily high-performance students who formed type-c judgments; poor performers tended to give type-a and type-b judgments. Future research would benefit from the use of our modified version of Koriat's framework in order to further explore how high and poor performing medical students differ in the way they form JOSs during communications skills training.
\end{abstract}

Michaela Wagner-Menghin

michaela.wagner-menghin@meduniwien.ac.at

1 Department of Medical Education (DEMAW), Medical University of Vienna, Spitalgasse 23, 1090 Vienna, Austria

2 Faculty of Health, Medicine and Life Sciences, School of Health Professions Education (SHE), Maastricht University, Maastricht, The Netherlands 
Keywords Communicating with patients - Directed content analysis · Judgment of satisfaction (JOS) · Metacognitive monitoring · Undergraduate medical students

\section{Introduction}

Effective communication with patients is crucial in making a correct diagnosis (Hampton et al. 1975; Peterson et al. 1992), devising an appropriate treatment plan (Chen et al. 2008), warranting doctors' well-being (Maguire and Pitceathly 2002), and ensuring that patients adhere to the prescribed treatment (Zolnierek and DiMatteo 2009). Learning to communicate effectively, however, requires deliberate practice in challenging settings (e.g. Ericsson 2008), which the medical workplace does not always provide. Medical schools therefore offer training programs with simulated patients aimed to teach students communication process skills (Yedidia et al. 2003), such as structuring, attentive listening and open-to-closed questioning techniques. When applying these skills to real patients in the clinic, however, students come across different communication cultures and struggle to harmonize the communication techniques they have learned with clinical reality and their personal communication style (Aper et al. 2015; Bombeke et al. 2012; Brown 2010; Hook and Pfeiffer 2007; Rosenbaum and Axelson 2013; Williams et al. 2001; Wouda and van de Wiel 2013).

As a remedy, it has been suggested that the training setting be more closely aligned with the clinical setting. Yet, patient communication will always require some degree of adaptation, as people differ and, consequently, no two situations will ever constitute a perfect match. Additionally, when something learned cannot be transferred smoothly, previous teaching has not yet succeeded in familiarizing students with relevant underlying principles. This might be traceable not only to the learning environment itself, but also to teachers' and students' way of using it (van Merriënboer 1997). The present study therefore seeks to expand the discussion on how to facilitate transfer of communication skills by taking a cognitive-psychological approach. More specifically, we focused on students' metacognitions, as these are important for learning how to apply the underlying communication principles in a new setting (e.g., when moving from classes to clinic, or from patient A to patient B). This approach will help us understand to what extent students have acquired relevant communication principles and how they use them.

Metacognition, originally defined as "thinking about your own thinking and cognitions" (Flavell 1979), is nowadays often framed within a self-regulation model. It is driven by two processes, monitoring and controlling, that link the actual situation with the knowledge and beliefs stored in the memory of the learner (Nelson and Narens 1990). Monitoring can be viewed as the internal evaluation process that precedes and informs the controlling of action. As such, metacognition is particularly relevant in patient communication, as it informs adaptation of behavior during the encounter (reflection in action), while afterwards (reflection on action) it guides further learning or practice (Schön 1983). When a student, for instance, poses an opening question that does not lead to a satisfactory answer, leaving the student with a sense of dissatisfaction (monitoring), he or she may immediately rephrase the question (controlling). After the encounter the student may decide to rehearse a variety of suitable opening questions to better integrate them into the verbal repertoire (controlling learning). 
To enact efficient control, however, monitoring needs to be accurate. When a student, for example, evaluates his or her performance too optimistically, inefficient learning behaviour (e.g., premature interruption of study or practice) and low learning outcomes will result (de Bruin et al. 2011; Dunlosky and Rawson 2012; Dunlosky and Thiede 2013; Koriat 2012a; Metcalfe and Kornell 2005; Thiede et al. 2003; van Loon et al. 2013). A better insight into the monitoring process may help improve its accuracy. The cue-utilization framework introduced by Koriat (1997) is useful to guide this insight: It states that learners form judgments by consciously and unconsciously selecting and processing different types of cues that the situation emits (cues = signals or hints one can percept in the

Table 1 Translating the cue-utilization framework from experimental learning research to communicating with patients

Source definition and examples:

experimental learning research
Translated definition and examples:

communicating with patients

Objectively identifiable cues: observable cues (extrinsic cues), OC

Definition Characteristics observable in the learning situation (Koriat 1997)

Examples Trials/time used for studying a learning material/text (Koriat 1997)

Number of arguments used to generate a summary about a text (Thiede and Anderson 2003)
What was done or said in the situation either by patient or by the student that can also be seen or heard by an observer

Student asks a series of closed questions The patient answers in a low voice with oneworded answers

Objectively identifiable cues: memory cues (intrinsic cues), MC

Definition Cues referring to beliefs and knowledge in memory

Examples Semantic relatedness of learning material [related (poker-flush) or unrelated (dogspoon)] (Koriat 1997)

Short-term memory representation of text [verbatim sentences] (Thiede et al. 2005)

Long-term memory representation of text [inferences made based on text] (Thiede et al. 2005)

Mnemonic cues/subjective feelings (SF)

Definition Unconscious processing of observable cues and memory cues which is experienced as subjective feeling. This unconscious cognitions are translated in a verbal expression in form of an object's attribute(Koriat 2012b)

Example Ease of text processing during reading- "It is easy to recall this list of words"

Ease of retrieval when deriving the selfjudgment (Koriat 1997)

Explicitly mentioned knowledge and beliefs when elaborating on a judgment

Such statements can be reliably identified by probing if the to be coded statement sounds like an answer in a knowledge test on communication skills

"Start the information gathering with an open question" (mental model)

"Have several versions of suitable opening questions available to use according to first impression of patient" (mental model)

"Try another opening question, when patient has not started talking or looks puzzled" (cognitive strategies)

Verbal elaborations including adjectives indicating that a comparison to an internal standard has taken place

"This question appears to be inappropriate" "I have chosen a suitable transition statement"

Definition of cues and examples 
situation, see Table 1, left column). To refer to judgments emerging from monitoring satisfaction with performing complex skills, we here introduce the term judgment of satisfaction (JOS). In the example above, observations (the patient provides too little information) and subjective feelings (discontent with the information obtained) are the cues that trigger student's negative JOS (=dissatisfaction) which in turn cause the student to adopt a different strategy.

Because not all cues at hand are equally relevant, misjudgments occur. Fortunately, when it comes to learning from text, we can guide students to select relevant cues. Strategies for this include activating relevant cues by having students reread a text (Dunlosky and Rawson 2005), generate summaries (Thiede et al. 2003) and utilize keywords (Thiede et al. 2005), as well as de-activating irrelevant cues by delaying monitoring until initial reading experiences (e.g., time spent and ease of reading) have disappeared from working memory. When the new objectively identifiable cues (length of summary) and new subjective feelings (ease of retrieval and processing fluency) remain, monitoring accuracy improves as these cues better predict the (quantifiable) degree of comprehension (Thiede et al. 2005).

Despite these insights on text comprehension, knowledge about how learners actually use cues to form JOSs when communicating with patients is scant, and there is a paucity of techniques facilitating the use of communication-specific cues. A study by Martin et al. (1998) revealed that monitoring improved after students had reviewed four videos showing other students interviewing a patient ( $\mathrm{r}=0.38$ before vs. $\mathrm{r}=0.52$ after) as it helped them to better understand the assessment criteria and differences in performance. How students processed cues to bring about such effect was not explored. In a similar vein, Hawkins et al. (2012) found that students' self-evaluation of their suturing performance improved (from $r=0.48$ to $r=0.83$ ) after having been shown several performances of other students on video. What deserves attention in this context is that student's monitoring accuracy influences how a supervisor delivers feedback to the student (Kogan et al. 2012) and what the student gains from this feedback (Eva et al. 2012). Knowing this, it becomes all the more important that we enhance students' monitoring accuracy during patient communication. However, before being able to do so, we need to know which communication-specific cues they use when forming a JOS and what themes these cues focus on.

In addition to building on Koriat's cue-utilization framework (1997), the present research will draw on theoretical principles from a conversational model for doctor-patient communication outlined by Silverman et al. (2005). Central to this model is the notion that content aspects and process skills should be combined adaptively to integrate doctor's and patient's position. The new, combined model has been visualized in Fig. 1 where the quadripartite arrow illustrates there are four types of cues involved that may influence students' JOS. The first two types of cues concern the student's observations about the patient's behavior or about his/her own behavior during the patient interview (observable cues/patient $[\mathrm{OC} / \mathrm{P}]$ and observable cues/student $[\mathrm{OC} / \mathrm{S}]$ ). Third are the subjective feelings (SF) the interview may evoke in the student. Last, there are memory cues (MC) at play which are cues that originate in the student's memory. In the ideal situation that Fig. 1 represents, student's memory is structured along principles of the conversational model. It contains both factual knowledge (mental model) about communication goals, process skills, content aspects and their interrelations, and procedural knowledge (cognitive strategies) on reaching the goal using process skills adaptively to cover relevant content aspects (depicted in Fig. 1 as 'student's mental representations in memory'). In summary, student's monitoring process can involve the processing of OC/S, OC/P, SF and MC leading up to a self-judgment about the way the patient interview was conducted. 


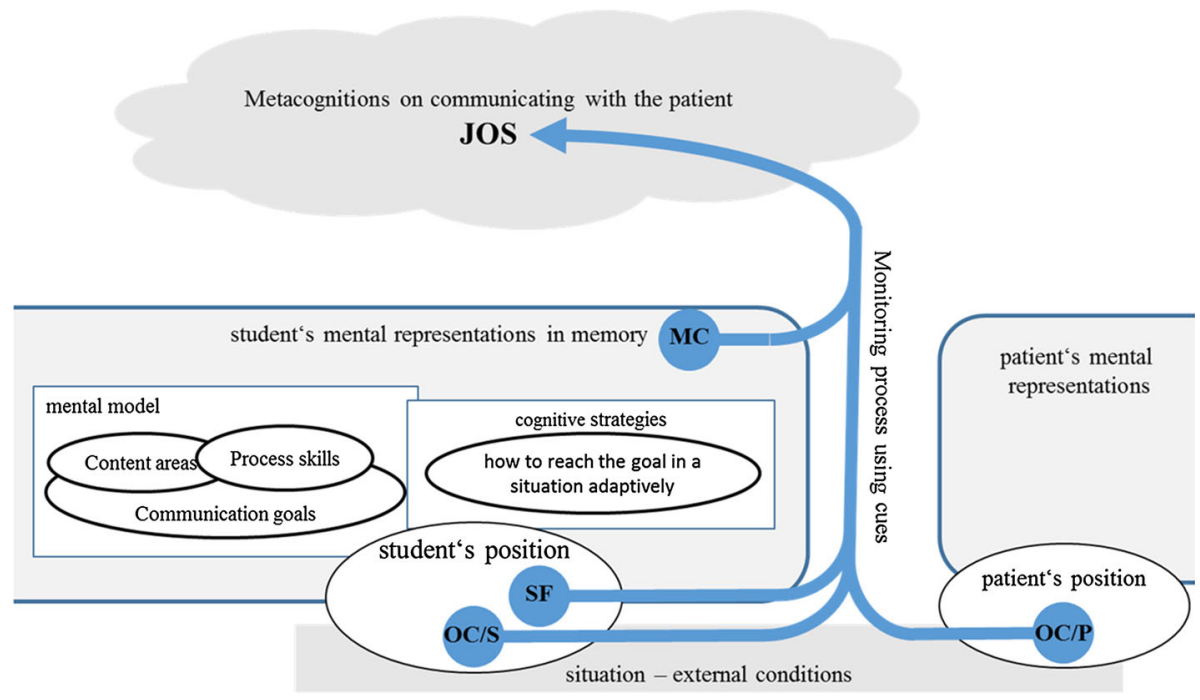

Fig. 1 Visualization of students' monitoring process during patient interviews that lead up to judgments of satisfaction, based on the theoretical constructs of Koriat's cue-utilization framework (1997) and Silverman et al.'s conversational model (2005). $M C$ memory cues, $O C / S$ observable cues student, $O C / P$ observable cues patient, $S F$ subjective feelings, JOS judgment of satisfaction

In view of the aforesaid, we hypothesize that:

1. the principles of Koriat's cue-utilization framework (1997) can be extrapolated to the realm of learning to interview patients. Students' metacognitive monitoring process during patient interviews relies on the cues $\mathrm{OC}$, SF and $\mathrm{MC}$ and involves an integration of the cues OC/S and OC/P to form judgments of satisfaction (JOSs); and

2. students, in spelling out their judgments about their own performances during patient interviews, will link their appropriate or inappropriate use of process skills to a corresponding effect on the quality and quantity of the information gathered.

\section{Methods}

We conducted a qualitative field study, having students complete a written assignment consisting of a metacognitive judgment task and some reflective prompts in their normal educational setting.

\section{Participants}

Our participants were second-year human medicine students of Medical University of Vienna. As part of the program, students received specific communication skills trainings with simulated patients (small group, 6 weeks, 90 min/week; based on Silverman et al. 2005), which were followed by an individual simulated patient practice appointment three months later. An OSCE-type practical clinical clerkship entry examination (PCCEx) ended the training. The written assignment that constituted the core input of our study was part of 
this examination. Of the 680 students who were enrolled, 524 (77 \%) consented to have their written assignments and PCCEx marks used for the study. As participation was voluntarily, we do not know why $23 \%$ opted out. We employed a stratified purposeful sampling technique (Sandelowski 2000) to achieve a sample of 20 information-rich cases. Six parameters were combined to form three layers, so-called strata, optimizing the sample for hypothesis-testing (Stratum 1) and controlling for possible confounders (Stratum 2 and 3; Table 2).

Table 2 Sampling parameter, their distribution for the sampling

\begin{tabular}{ll}
\hline Strata & $\%$ total $n=524$ \\
Sampling parameter & \\
$\quad$ Available characteristics & \\
\hline
\end{tabular}

Stratum 1

Patient role ${ }^{\mathrm{a}}$

Exploring pain (knee)—emergency outpatient department $\quad 18$

Embarrassed patient (pain when urinating)—urology outpatient department 24

Chronic illness likely (diarrhoea)_internal medicine outpatient department 29

Non-compliant patient (transfer to inpatient dep.) — cardiology department 19

Worried patient (node $=$ cancer?) —internal medicine outpatient department $\quad 10$

Performance in PCCEx and history taking station ${ }^{\mathrm{b}}$

$\begin{array}{ll}\text { Excellent performers } & 29\end{array}$

Good performers $\quad 52$

$\begin{array}{lr}\text { Satisfactory performance } & 12\end{array}$

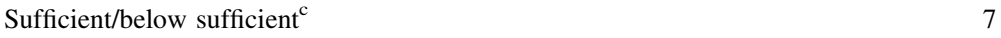

Stratum 2

Communication class-training groups

68 training groups $(\sim 10$ students/group $) / 40$ teachers $^{\mathrm{d}}$

Stratum 3

Sex students

Male $\quad 56$

Female $\quad 44$

Sex simulated patient (SP); 14 male/15 female actors ${ }^{\mathrm{e}}$

Encounters with male SP $\quad 55$

$\begin{array}{ll}\text { Encounters with female SP } & 45\end{array}$

Realizable: $6 \mathrm{~m} / \mathrm{f}, 5 \mathrm{f} / \mathrm{m} ; 5 \mathrm{f} / \mathrm{f} ; 4 \mathrm{~m} / \mathrm{m}$

PCCEx, OSCE-type practical clinical clerkship entry exam

${ }^{\mathrm{a}} \mathrm{n}$ of patient roles depends on the availability of actors on the training day, actors play more than one case but not all cases, this could not be controlled due to the complexity of students' and actors' schedule

b Performance in history taking station had to be combined with the PCCEEx performance to improve reliability, to keep validity of the sampling cases with little variance between and history taking station were preferred

c Defined by a modified Angoff-standard-setting procedure

d $4 \mathrm{~h}$ standardized teacher training to ensure teaching quality between the groups, 1-3 groups per teacher

e $3 \mathrm{~h}+3 \mathrm{~h}$ standardized patient training, mean number of role play $=17, \mathrm{~s}=11$ 
Stratum one considered differences in case difficulty and students' learning ability as measured by the PCCEx, because students with higher metacognitive abilities have generally been shown to perform better compared to students with lower metacognitive abilities (Dunlosky and Rawson 2012). The four ability levels combined with the five different patient roles led to a sample of at least 20 cases, which we sampled from 20 different training groups (Stratum 2) and controlled for actor and the sex of student and actor (Stratum 3). Students' age was not assessed, based on cohort's enrolment data the expected age range is between 20 and 25 years. The language of instruction was German.

\section{Materials}

\section{Simulated-patient encounter and video-recording}

All students video-recorded their simulated patient practice encounter. Actors were advanced medical students who were trained to interpret five typical patient roles, relevant for clinical clerkships (see Table 2). Students choose a role they liked to practice.

\section{Metacognitive judgment task and written assignment}

Students were instructed to review their video and select relevant scenes about which they clearly felt satisfied or dissatisfied with respect to their performance. They then answered the following question: "How satisfied are you with the selected scene?" (not satisfied/very satisfied). Finally, they were invited to elaborate on their JOS in writing ("Briefly describe what is happening in the selected scene' and 'Explain why you are satisfied/not satisfied with this scene').

\section{Procedure}

Before video-recording the encounter, students received a form with basic information about the study and a consent statement. They then completed the written assignment which was later discussed in a PCCEx station. It was emphasized that the focus of the assignment was their ability to analyze strengths and weaknesses, similar to small group practice.

\section{Analysis}

We performed a directed content analysis (Hsieh and Shannon 2005) by classifying text representing similar meaning into categories. The key concept behind this approach is that existing theory guides the initial coding of categories, also called deductive category application (Mayring 2000), while allowing for the revision of coding categories and their definitions in reaction to the text. Hence, for validating or conceptually extending a theory or theoretical framework like the cue-utilization framework, it can be a powerful tool. We used Atlas.ti (1993-2014) to manage the category application and to derive the category's frequency counts.

\section{Unitizing}

Students' elaborations on their judgments, hence not the patient interviews themselves, were transcribed and organized into propositional units (propositional distinction of units, 
Krippendorf 2004) that were structured as follows: "I am satisfied/not satisfied with $\mathrm{X}$ because I did/observed/perceive Y, which I know/believe to be Z".

\section{Deductive category application}

From our integrated model represented in Fig. 1 we derived the two coding dimensions 'types of cues used' and 'themes mentioned in elaboration'. Their reliability was checked formatively (Mayring 2000) by constantly comparing the assigned statements.

Types of cues used This dimension was inspired by Koriat's cue-utilization framework (Koriat 1997), while Silverman et al.'s conversational model (Silverman et al. 2005) served to further embellish its categories (see Table 1, right column, for a specification).

Themes mentioned in elaboration This dimension built entirely on the conversational model. We derived the two nominal categories 'content aspects' (CA) and 'process skills' (PS) and divided them into three and eight subcategories, respectively. Within the CA category we distinguished the subcategories 'biomedical perspective (CA/BP)', 'patient's perspective (CA/PP)', and 'background information (CA/BI)' defined according to Silverman et al. (2005, p. 19). For the PS subcategories we modified Silverman et al.'s definition (2005, p. 20-23, p. 28) to reduce ambiguity and enhance coder consistency: 'questioning style (PS/QS)', 'attentive perception (PS/AP)', 'facilitative response (PS/ $\mathrm{FR})$ ', 'picking up cues (PS/PuC)', 'providing structure (PS/PStr)' as well as 'building the relationship-(non-)verbal behaviour/expressing attitude towards patient (PS/nVB-att.) and 'building the relationship-appropriate use of language (PS/AuL)'. (A detailed description of modification and examples can be obtained from the first author).

\section{Quantitative steps of analysis}

To enhance our qualitative interpretation, we counted frequencies of code occurrence and pairwise co-occurrence (c-index) of theoretically relevant categories. The $c$-index (ATLAS.ti GmbH 1993-2014), rooted in quantitative content analysis normalises the cooccurrence frequencies (c-index $=\mathrm{n} 12 /(\mathrm{n} 1+\mathrm{n} 2)-\mathrm{n} 12 ; \mathrm{n} 12=$ co-occurrence frequency of two codes $c 1$ and $c 2, n 1$ and $n 2$ being their respective occurrence frequency). It varies between 0 and 1 , where 0 indicates that the two codes never co-occur and 1 that they do so in all instances. We use the following, arbitrary set, levels of co-occurrence: low degree ( $c<0.25$; meaning both codes are used in $<25 \%$ of the cases), medium degree ( $c \geq 0.25$ and $<0.75)$, and high degree $(c \geq 0.75)$.

\section{Results}

\section{Unitizing: identifying expressions}

Principal investigator MWM and a German-speaking research assistant unitized the material. The number of scenes selected to form a JOS varied between students $($ Mean $=3.3, \mathrm{SD}=1.2, \min =1, \max =5)$, as did the number of expressions (Mean 1.9, $\mathrm{SD}=1.2, \min =1, \max =7$ ) they needed to elaborate each JOS. Twenty students provided a total of $67 \mathrm{JOSs}$, with 133 expressions. Scenes students were dissatisfied with 
(61\%) generally outnumbered those they were satisfied with (39\%). This also holds for the individual student as shown by the low mean ratio of positive judgments to total number of judgments $\left(\mathrm{JOS}_{\text {ratio }}\right.$ per student) (Table 3).

\section{Deductive category application}

MWM and AdB coded a subset of 15 randomly chosen statements jointly to test the initial definition of nominal categories and subcategories. The remaining statements were coded by MWM and a research assistant.

\section{Types of cues used (hypothesis 1)}

\section{Observable cues, subjective feelings, memory cues}

The OC/S, OC/P, MC and SF codes were easy to assign. A typical example of an OC/S, in which the student elaborates on what he or she did, is the following: "Ask about partner, Contraception, Point out STD-I stuttered too much, I could not find the appropriate words. [...].' (P8). Quite different is the next example of an OC/P code, in which the student reflects on what the patient said: 'The patient reports burning pain when urinating, started anew two weeks ago, [...].' (P12). Some expressions required the joint assignment of OC/P and $\mathrm{OC} / \mathrm{S}$ codes, for instance in the following example where the student elaborates on what the patient said and what he or she did in response: 'Question about urine and stool: After receiving "normal" for an answer I asked the suggestive questions "brown?", "not often?"' (P43). The expressions we labelled as SF-cues typically included adjectives referring to the quality, quantity or the suitability of an action in the scene: 'I asked the patient if her parents were still alive. The question was not phrased well $\rightarrow$ too straightforward, too direct' (P32). Finally, a typical example of an MC would read: 'Suggestive questions cause many patients to agree and to stop telling other details even if they wanted to tell something' (P28).

Students tended to base their judgments more frequently on observations of their own behavior (in $57 \%$ of the expressions) rather than the patient's (in $31 \%$ of the expressions).

Table 3 Unitizing-descriptive results

\begin{tabular}{|c|c|c|c|c|}
\hline & Mean & SD & $\mathrm{N}$ & $\%$ unit \\
\hline Student as unit & - & - & 20 & - \\
\hline Number of JOSs per student & 3.3 & 1.2 & - & - \\
\hline $\mathrm{JOS}_{\text {ratio }}$ per student $=\mathrm{JOS}_{\text {satisfied }} /\left(\mathrm{JOS}_{\text {satisfied }}+\mathrm{JOS}_{\text {not satisfied }}\right)$ & 0.38 & 0.26 & - & - \\
\hline JOS as unit & - & - & 67 & - \\
\hline $\mathrm{JOS}_{\text {satisfied }}$ & - & - & 26 & 39 \\
\hline JOS $_{\text {not satisfied }}$ & - & - & 41 & 61 \\
\hline Number of expressions ${ }^{\mathrm{a}}$ per JOS & 1.9 & 1.2 & - & - \\
\hline Duration of scenes selected for JOS (min:sec) & $1: 25$ & $1: 41$ & 67 & - \\
\hline Expression as unit & - & - & 133 & - \\
\hline
\end{tabular}

${ }^{a}$ Expressions that could be arranged into propositional units of the type: "I am satisfied/not satisfied with $X$ because I did/observed/perceive Y, which I know/believe to be Z" 
We expected a theoretically relevant co-occurrence of the cues OC/S and OC/P, as this is essential to integrate behavioral information of both interactors. Surprisingly, we found that these cues were used jointly in only $21(16 \%)$ of the expressions, while the c-index of 0.22 signaled only a low to medium degree of co-occurrence. This also means that hypothesis 1 could not be fully confirmed. As this joint usage of OC/S and OC/P cues is important for effective patient communication, we suggest that this topic be subjected to further scrutiny. In regards to the categories SF and MC, these were used in $61(46 \%)$ and $35(26 \%)$ expressions, respectively (Table 4$)$.

\section{Revision of categories in reaction to the text}

The joint reading and coding process revealed that the Koriat-inspired array of cues with which we started the analysis failed to represent important expression segments. What these segments shared was that they integrated MC with situationally available information to form a judgment, which, in turn, served as cue that led up to a JOS. Unlike subjective feelings that are independent of content, these judgments were content-specific. We therefore coined them 'proxy judgments (PJ)' and added them to our cue repertoire. A refinement of this new category led to the inclusion of three conceptually relevant subcategories, being 'summative behavior (PJ/SUB)', 'forgot to ask something (PJ/FTA)' and 'interpreting patient's experience (PJ/IPE)' which receive further clarification in the next paragraphs.

The first proxy judgment, 'summative behavior (PJ/SUB)', manifests itself when a student uses attributes or adjectives to describe apparently observed behavior. For instance in the sentence'... the questions were rather general...' the attribute 'general' qualifies the 'questions'. As the student cannot determine whether a question is 'general' purely based on observations, he or she must draw from previous knowledge, in this example from the skills acquired through communication skills training to distinguish between open-ended and closed-ended questions, and between general and specific questions.

Table 4 Observable cues, subjective feelings, memory cues and proxy judgments: frequencies, theoretically relevant co-occurrence

\begin{tabular}{llll}
\hline $\begin{array}{l}\text { Category } \\
\text { Subcategory }\end{array}$ & $n$ & $\%$ total $n=133$ & c-index \\
\hline Observable cues (OC) & 96 & 72 & - \\
Student-emitted (OC/S) & 75 & 57 & - \\
Patient-emitted (OC/P) & 41 & 31 & - \\
Co-occurrence OC/S and OC/P & 21 & 16 & - \\
OC/S unique & 55 & 42 & - \\
OC/P unique & 20 & 15 & - \\
Subjective feelings (FS) & 61 & 46 & - \\
Memory cues (MC) & 35 & 26 & - \\
Proxy judgments (PJ) & 72 & 54 & - \\
Summative behavior (PJ/SUB) & 39 & 29 & - \\
Forgot to ask (PJ/FTA) & 24 & 18 & - \\
Interpreting patient's experience or behavior (PJ/IPE) & 17 & 13 & - \\
\hline
\end{tabular}


Second, we assigned the code 'forgot to ask something (FTA)' when students reported being dissatisfied because they forgot to ask something. Since you cannot actually observe the absence of a question, such statements could not be classified as OC, which we would have done in the reverse case-if a student reported having asked a question. Hence, again, prior knowledge, in this case about what had to be asked, needs to be activated, although none of these statements included explicit elaborations on what exactly should have been asked. Finally, the proxy judgment 'Interpreting patient's experience (IPE)' was coded when students elaborated on how they interpreted the patient's experience in the situation, for example: 'patient is in an unfavorable and difficult situation'.

The finding that $72(54 \%)$ of all expressions contained proxy judgments, reinforces our expansions of Koriat's cue repertoire (Table 4). We found proof that students indeed employ the specified cues OC/S, OC/P, SF and MC, however, given the complexity of the domain, we have also found that there are at least three additional cues, the so called proxy-judgments (PJ), at play.

\section{Themes mentioned in elaboration (hypothesis 2)}

\section{Content aspects and process skills}

Examining what themes students focus on when elaborating on their JOSs, we experienced no difficulty in pinpointing content aspects (CA). A typical example, in which the student focuses on his/her neglect to discuss relevant content (in this case: background information), is the following: I am 'not satisfied' with this sequence, because ... 'doing an internal summary on Personal and Social History, I realized I did not talk about sexually transmitted diseases and his ex-girlfriend'. (P9) A typical example of a focus on process skills (PS), by contrast, would read (in this case: providing structure to the consultation): I am 'not satisfied' with this sequence, because ... 'taking past medical history, family history and review of systems I did not use good transition statements, also I lost track and paused between two parts'. (P54) When assigned PS together with CA codes, themes were interlinked by words like 'because'. For instance: I am 'very satisfied' with this sequence, because ... 'I asked the patient about his current complaints, why he is in the ambulance today, about pain, quality and when they began (...) Doing this I learnt a lot about the patient's current problem, because I kept asking and kept waiting and asking' which I know/believe: ... 'in order to motivate the patient to talk'. (P57; expression 1)

Regarding frequencies, we found these to be high for both CA (44\%) and PS (68\%). The content aspects were more often related to background information $(\mathrm{CA} / \mathrm{BI})$ than to biomedical perspective $(\mathrm{CA} / \mathrm{BP})$ while they hardly ever concerned the patient's perspective (CA/PP). The counts for co-occurrence of PS with CA, however, were low, with only $12 \%$ of the expressions connecting the application of process skills with the quality or quantity of the content aspects. The c-index of 0.12 also indicates a low degree of cooccurrence. The process skills students reflected on most often were 'questioning style' $(14 \%)$, 'attentive perception' (14\%) and 'relationship-building based on verbal or nonverbal behavior' (15\%) (Table 5).

Although we had no difficulty in applying the principles of Silverman's conversational model to our analysis, to the extent that we could indeed group students' judgments along the themes 'content aspects' and 'process skills', hypothesis 2 could not be fully confirmed. 
Table 5 Themes mentioned in elaboration: frequencies, theoretically relevant co-occurrence

\begin{tabular}{|c|c|c|c|}
\hline $\begin{array}{l}\text { Category } \\
\text { Subcategory }\end{array}$ & $n$ & $\%$ total $n=133$ & c-index \\
\hline Content area (CA) & 58 & 44 & - \\
\hline Biomedical perspective (CA/BP) & 13 & 10 & - \\
\hline Patient's perspective (CA/PP) & 4 & 3 & - \\
\hline Background information (CA/BI) & 42 & 32 & - \\
\hline Process skills (PS) & 91 & 68 & - \\
\hline Questioning style (PS/QS) & 19 & 14 & - \\
\hline Attentive perception (PS/AP) & 19 & 14 & - \\
\hline Picking up cues (PS/PuC) & 10 & 8 & - \\
\hline Facilitative response (PS/FR) & 9 & 7 & - \\
\hline Building the relationship (PS/BR) & & & - \\
\hline (Non-)verbal behav./att. (PS/BR/nVB) & 20 & 15 & - \\
\hline Appropriate use of language (PS/BR/AuL) & 11 & 8 & - \\
\hline Providing structure (PS/PStr) & 13 & 10 & - \\
\hline Co-occurrence (CA and PS) & 16 & 12 & 0.12 \\
\hline CA unique & 42 & 32 & - \\
\hline PS unique & 75 & 56 & - \\
\hline Co-occurrence (CA and PS)-topics & & - & - \\
\hline PS/QS $\rightarrow$ information’s quality & 1 & - & - \\
\hline PS/AP $\rightarrow$ information's quality & 5 & - & - \\
\hline PS/AP $\rightarrow$ communication's quality & 3 & - & - \\
\hline $\mathrm{PS} / \mathrm{PuC} \rightarrow$ information's quality & 1 & - & - \\
\hline $\mathrm{PS} / \mathrm{PuC} \rightarrow$ communication's quality & 3 & - & - \\
\hline PS/FR $\rightarrow$ information's quality & 1 & - & - \\
\hline PS/BR $\rightarrow$ information's quality & 2 & - & - \\
\hline PS/PStr $\rightarrow$ communication's quality & 2 & - & - \\
\hline
\end{tabular}

\section{Three types of JOSs}

In retrospect, we can distinguish three types of JOSs which differ in focus: judgments that focus (1) on content (JOS-type-a: information quality/quantity); (2) on process skills (JOStype-b: communication technique quality); and (3) on the appropriateness of the process skill utilized in view of the goal to be attained (JOS-type-c: situational appropriateness). These JOSs-types also differ regarding the numbers of satisfaction/dissatisfaction judgments and numbers of high/poor performers in the PCCEx (Table 6). Thus we believe that further application of this distinction may facilitate future research into the essentials of effective patient communication. A summary of JOS-types and examples are displayed in Table 7.

\section{Discussion}

This study adopted a cognitive-psychological approach to students' problems in transferring communication skills from medical school's simulation training to clinical practice by focusing on the metacognitive processes involved. We adapted Koriat's cue-utilization 
Table 6 Contingency table presenting the counts of satisfaction/dissatisfaction judgments and of high/poor performers in the PCCEx for each JOS-type (c-index in parentheses)

Themes mentioned in elaboration

\begin{tabular}{ll}
\hline Content aspects (CA) Process skills (PS) & $\begin{array}{l}\text { Content aspects and process } \\
\text { skills (CA and PS) }\end{array}$
\end{tabular}

Expressions from satisfaction/dissatisfaction judgments

$\begin{array}{lccc}\text { Satisfaction } & 16(0.38) & 27(0.36) & 9(0.56) \\ \text { Dissatisfaction } & 26(0.62) & 48(0.64) & 7(0.44) \\ \text { Expressions from high/poor performers } & & 15(0.93) \\ \text { High performers } & 20(0.47) & 53(0.71) & 1 \text { (n.a.) } \\ \text { Poor performers } & 22(0.45) & 22(0.29) & \end{array}$

Italicized values represent the c-indexes exceeding the arbitrarily set value of $c>0.25$

High performers = students with good to excellent performance in the practical clinical clerkship entry exam (PCCEx); poor performers = students with insufficient to satisfactory performance in PCCEx

Table 7 Three types of JOSs, definition, relation to external criteria, examples

\begin{tabular}{|c|c|}
\hline JOS-type ${ }^{a}$ & Example \\
\hline $\begin{array}{l}\text { (a) Completeness (or the lack thereof) } \\
\text { of covered content } \\
\text { 1. No relation to PCCEx } \\
\text { 2. more dissatisfaction than } \\
\text { satisfaction expressions }\end{array}$ & $\begin{array}{l}\text { (P58, E1): very satisfied; Family history, checking if there are } \\
\text { further illnesses common in her family. After she had answered } \\
\text { about her father's heart attack I ask [...] } \\
\text { (P9, E2): not satisfied; Doing an internal summary on Family } \\
\text { History I have not talked about sexually transmitted diseases and } \\
\text { former sexual partners }\end{array}$ \\
\hline $\begin{array}{l}\text { (b) Quality of performing a process } \\
\text { skill } \\
\text { 1. More often provided by PCCEx } \\
\text { high performers } \\
\text { 2. More dissatisfaction than } \\
\text { satisfaction expressions }\end{array}$ & $\begin{array}{l}\text { (P22, E1): very satisfied; I am exploring problems in daily life, } \\
\text { support, significant others, stress; good, that my questions where } \\
\text { rather general (talkative patient) } \\
\text { (P13, E1): not satisfied; Patient talks about [...] "uh regarding } \\
\text { your [...], you feel good about [...]"; do not think aloud, do not } \\
\text { say "you feel good about"-suggestive statement }\end{array}$ \\
\hline $\begin{array}{l}\text { (c) Appropriateness of process skill to } \\
\text { reach goal } \\
\text { 1. Nearly all expressions provided by } \\
\text { PCCEx high performers }\end{array}$ & $\begin{array}{l}\text { (P28, E1) very satisfied; The patient tells me about }[\ldots] . \text { I let (her) } \\
\text { talk as she wishes and I listen attentively }[\ldots] \text { she is telling a lot } \\
\text { and long } \rightarrow \text { thus patient experiences that her fears are heard } \\
\text { here }\end{array}$ \\
\hline $\begin{array}{l}\text { 2. No systematic relation with } \\
\text { satisfaction/dissatisfaction }\end{array}$ & $\begin{array}{l}\text { (P12, E1) not satisfied; The patient reports }[\ldots] .[\ldots] \text { explored } \\
\text { localization not precisely enough, doubt concerning this runs } \\
\text { through the rest of the encounter, I probably was too self- } \\
\text { conscious because of the "intimate localization } \rightarrow \text { not } \\
\text { professional }\end{array}$ \\
\hline
\end{tabular}

\footnotetext{
${ }^{a}$ Cells contain the following information: (1) relation with level of performance in the practical clinical clerkship entry exam (PCCEx; high performers = students with good to excellent performance; poor performers = insufficient to satisfactory performers: (2) relation with satisfaction/dissatisfaction judgments
}

framework of metacognitive monitoring (1997) to analyze how students monitor the process of learning to interview patients. Our study confirmed that students do indeed employ the cues defined by the cue-utilization framework to form JOSs when monitoring their history-taking performance. Hence, we found the cue-utilization framework to be a useful tool for analyzing metacognitive processes involved in history-taking. 
Yet, we also found that in order to fully capture the complexity of patient communication, the framework required expansion. Therefore, we introduced three new domainspecific cues, coined proxy judgments (PJ). Whilst one of these focused on the goal to obtain the desired information from the patient (PJ/FTA), another was particularly geared towards interpreting the patient's experience and behavior (PJ/IPE). A third cue evolved when students used adjectives and adverbs to summarize behavior they felt they observed (PJ/SUB). This is striking, as accepted rules for providing student feedback discourage the use of summative behavior descriptors because specific descriptive statements comparable to the cue-utilization framework's OC are more easy to translate into behavioral changes (Kurtz et al. 2005). Our findings, however, suggest that a summative behavior proxy judgment, which arises effortlessly in the student's mind, may have a powerful indicator function. It signals students a need to explore behavior in more detail. However, this explanation requires further testing.

Our findings also demonstrated that the JOSs students form when monitoring their history-taking performance can be three in kind, depending on the theme or themes they focus on. In the case of the first two types, tagged as 'JOS-type-a' and 'JOS-type-b', judgments were based exclusively on either content (a) or the quality of the communication technique (b). When forming an a-type JOS, students went at lengths to check all items of the content list dictated by the course material, leaving them dissatisfied if certain topics on the checklist could not be covered. Evidently, at this early stage of training, students still lacked the skills to tailor their communication strategies to clinical reasoning, being unable to judge which items were relevant or not and being overly concerned with coverage of content instead. When forming a b-type JOS students were committed to applying the communication techniques in the exact way their teachers had taught them. Being able to harness and execute these process skills gave cause for satisfaction.

Typically, neither a-type nor b-type JOSs included reflections on how student's communication strategy affected the patient and his/her narrative. The limited number of judgments that did consider this relationship belong to the JOSs of type c: by balancing the appropriateness of the communication technique employed in view of the goal to gather the information needed for a correct initial diagnosis, students exhibited behavior that teachers wish to encourage in students (Silverman et al. 2005). The finding that such judgments are rare at this stage of education finds resonance in previous medical education research. A qualitative study on the acquisition of consultation skills, for instance, revealed that, when judging the quality of observed and performed consultations during clerkships, only a few students considered how their communication strategies affected the patient. The study concluded that integrating good patient communication with clinical reasoning is a skill medical students find extremely difficult to master (Aper et al. 2015).

At face value our results may seem to replicate previous findings emphasizing that students tend to specifically identify scenes they are dissatisfied with (Hulsman and van der Vloodt 2015). When considering the distribution of positive and negative judgments for each JOS type, however, our findings shed new light on this matter. While judgments of types a and b were indeed predominantly negative (=dissatisfied), those of type c, however, appeared to be more evenly distributed between positive and negative judgments. On further scrutiny of the process skills students were dissatisfied with, we moreover gained the striking insight that students at this educational stage lack sufficient verbal repertoire to implement the process skills. This was reflected in the high number of students' utterances about appropriate language usage (PS/BR/AuL). Our study therefore provides empirical evidence that at least some students need additional help in developing a verbal repertoire. Discussing our results with our teachers, actors and some students, they remembered 
situations where actors interviewed by students who lacked adequate vocabulary even made jokes, such as "learn your text" or "you lack verbal repertoire for this improvisation". They also observed that some students, to remedy their shortcomings, began listening closely to other students' role play in order to capture good verbal expressions and left the course with a list of questions or phrases for all sorts of situations.

\section{Limitations}

Some limitations to this study are worth noting. First, to smooth instructions and to prevent misunderstandings as to how the assignment should be performed, we decided to work with a dichotomous judgment scale. During the analysis we found this to be a disadvantage, because we could no longer distinguish the particular weights students attached to the selected scenes and their respective judgments. Studies on similar metacognitive assessments, such as judgments of diagnostic certainty, employ a wider scale (Cavalcanti and Sibbald 2014). We therefore suggest that future studies on JOSs about performance follow their example.

Next, partly due to the pilot character of the study and the complexity of the domain, we did not set students' metacognitive judgments against an external standard in order to determine their accuracy. Hence, although our study brought to light which cues students employed, we cannot make any predictions about their usefulness. Future studies will need to address this and compare students' judgments to benchmark judgments. This is all the more important since students' self-judgment capabilities play a key role in facilitating the delivery of feedback by faculty (Eva et al. 2012; Kogan et al. 2012). An experimental study by Cavalcanti and Sibbald (2014) into the relation between diagnostic certainty and diagnostic accuracy during physical examination effectively deployed simulators as standardized stimulus material. We may well derive inspiration from this example-a possible modification for instance, would be to use a well-defined set of pre-rated stimulus videos instead of students' own videos to investigate their judgment behavior.

There is also no objective measure to determine whether the sequences selected by the students to derive a JOS are relevant sequences as compared to an external standard. Students may have felt obliged to select sequences to elaborate on them resulting in JOS-type-a and JOS-type-b, likely easier to report on than the JOS-type-c. This assumption is supported by the small number of JOS-type-c. But because JOS-type-c accumulate among some highperformance students, whom we expect to have performed well when training history taking, we consider this explanation less likely. The question if those high performing students have already progressed further in their skill acquisition because of a difference in general ability, or because they had more or a different sort of teaching, can currently not be answered.

\section{Conclusion}

When progressing from novice to expert in communicating with patients, medical students face two challenges. First, they come to medical school with their own style of communicating. Experiencing the need for modifying or expanding it means to change secure routines and is thus a source of uncertainty (e.g. Ericsson 2008). Second, communicating always requires preparing for something new and/or surprising. Using communication techniques will only enhance the probability that the encounter goes well and that the taken history informs the clinical reasoning. However, like in performing arts, there is no guarantee it really turns out well. Using the cue-utilization framework for analyzing 
students' metacognitions facing these challenges in history taking enabled us to describe students' reflections on their learning of history taking. Thus we expand the focus of systems for describing reflections suggested elsewhere (Hulsman and van der Vloodt 2015), by allowing detailed analysis of the monitoring process based on an experimentally proven judgment model. A main finding is that students' metacognitive judgments focus on two communication-specific themes, being the quality and appropriateness of implemented communication skills (JOS-type-b) and the effect good communication has on the patient and on the quality of the information gathered (JOS-type-c). In studies on consultation skills acquisition, the students relating their performance to what effect their behavior has on the patients seemed to be the ones least afflicted by the shift between training and clinical setting (Aper et al. 2015). Thus, in order to foster transfer from training to clinical setting, future studies should focus on explaining why students expressed only few JOStype-c judgments.

Our study also reveals students' concern about covering content as specified by a checklist, rather than reflecting about covering content meeting medical needs, which could potentially inhibit the further development of history taking skills. Discussing how to change that should be the subject of future studies, as having students practice incorporating good patient communication with medical thinking on very easy problems has been shown to be considered important for identity formation (Aper et al. 2015). We found first hints that high-performance students are better able to integrate patient-emitted with student-emitted cues while focusing on the goal of history taking. Thus, the modified cueutilization framework can be used in the future to describe more closely how high-performing students and low-performing students differ in generating JOS when taking new patients' history.

We also hope our findings on the usefulness of the cue-utilization framework for analyzing medical students' cognitive processes when practicing a complex practical skill will stimulate further research on how students arrive at metacognitive judgments, like satisfaction or confidence judgments regarding their mastering of complex skills. Such results would be valuable for all educators responsible for developing skills training.

Acknowledgments Our thanks go to Tim Dornan, who took the effort to discuss suitable steps for the qualitative analysis with us, to Jan van Dalen who provided an early draft of this work with useful ideas, to Angelique van den Heuvel for magically transforming our German/Dutch-English into English-English and to Michael Schmidts, Martin Lischka and Siegfried Meryn for supporting this study.

\section{References}

Aper, L., Veldhuijzen, W., Dornan, T., van de Ridderd, M., Koole, S., Derese, A., \& Reniers, J. (2015). "Should I prioritize medical problem solving or attentive listening?" The dilemmas and challenges that medical students experience when learning to conduct consultations. Patient Education and Counseling, 98(1), 77-84. doi:10.1016/j.pec.2014.09.016.

ATLAS.ti GmbH. (1993-2014), atlas.ti7 qualitative data analysis. Berlin (Germany): ATLAS.ti GmbH.

Bombeke, K., Symons, L., Vermeire, E., Debaene, L., Schol, S., De Winter, B., \& Van Royen, P. (2012). Patient-centredness from education to practice: The 'lived' impact of communication skills training. Medical Teacher, 34, E338-E348. doi:10.3109/0142159x.2012.670320.

Brown, J. (2010). Transferring clinical communication skills from the classroom to the clinical environment: Perceptions of a group of medical students in the United Kingdom. Academic Medicine, 85(6), 1052-1059. doi:10.1097/ACM.0b013e3181dbf76f.

Cavalcanti, R. B., \& Sibbald, M. (2014). Am I right when I am sure? Data consistency influences the relationship between diagnostic accuracy and certainty. Academic Medicine, 89, 107-113. doi:10. 1097/acm.0000000000000074. 
Chen, R. C., Clark, J. A., Manola, J., \& Talcott, J. A. (2008). Treatment 'mismatch' in early prostate cancer-Do treatment choices take patient quality of life into account? Cancer, 112, 61-68. doi:10. 1002/cncr.23138.

de Bruin, A. B. H., Thiede, K. W., Camp, G., \& Redford, J. (2011). Generating keywords improves metacomprehension and self-regulation in elementary and middle school children. Journal of Experimental Child Psychology, 109, 294-310. doi:10.1016/j.jecp.2011.02.005.

Dunlosky, J., \& Rawson, K. A. (2005). Why does rereading improve metacomprehension accuracy? Evaluating the levels-of-disruption hypothesis for the rereading effect. Discourse Processes, 40, 37-55. doi:10.1207/s15326950dp4001_2.

Dunlosky, J., \& Rawson, K. A. (2012). Overconfidence produces underachievement: Inaccurate self evaluations undermine students' learning and retention. Learning and Instruction, 22, 271-280. doi:10. 1016/j.learninstruc.2011.08.003.

Dunlosky, J., \& Thiede, K. W. (2013). Four cornerstones of calibration research: Why understanding students' judgments can improve their achievement. Learning and Instruction, 24, 58-61. doi:10.1016/ j.learninstruc.2012.05.002.

Ericsson, K. A. (2008). Deliberate practice and acquisition of expert performance: A general overview. Academic Emergency Medicine, 15, 988-994. doi:10.1111/j.1553-2712.2008.00227.x.

Eva, K. W., Armson, H., Holmboe, E., Lockyer, J., Loney, E., Mann, K., \& Sargeant, J. (2012). Factors influencing responsiveness to feedback: On the interplay between fear, confidence, and reasoning processes. Advances in Health Sciences Education, 17(1), 15-26. doi:10.1007/s10459-011-9290-7.

Flavell, J. H. (1979). Metacognition and cognitive monitoring. A new area of cognitive-developmental inquiry. American Psychologist, 34, 906-911. doi:10.1037/0003-066x.34.10.906.

Hampton, J. R., Harrison, M. J. G., Mitchell, J. R. A., Prichard, J. S., \& Seymour, C. (1975). Relative contributions of history-taking, physical-examination, and laboratory investigations to diagnosis and management of medical outpatients. British Medical Journal, 2, 486-489.

Hawkins, S. C., Osborne, A., Schofield, S. J., Pournaras, D. J., \& Chester, J. F. (2012). Improving the accuracy of self-assessment of practical clinical skills using video feedback-The importance of including benchmarks. Medical Teacher, 34(4), 279-284.

Hook, K. M., \& Pfeiffer, C. A. (2007). Impact of a new curriculum on medical students' interpersonal and interviewing skills. Medical Education, 41(2), 154-159. doi:10.1111/j.1365-2929.2006.02680.x.

Hsieh, H.-F., \& Shannon, S. E. (2005). Three approaches to qualitative content analysis. Qualitative Health Reseach, 15, 1277-1288.

Hulsman, R. L., \& van der Vloodt, J. (2015). Self-evaluation and peer-feedback of medical students' communication skills using a web-based video annotation system. Exploring content and specificity. Patient Education and Counseling, 98(3), 356-363. doi:10.1016/j.pec.2014.11.007.

Kogan, J. R., Conforti, L. N., Bernabeo, E. C., Durning, S. J., Hauer, K. E., \& Holmboe, E. S. (2012). Faculty staff perceptions of feedback to residents after direct observation of clinical skills. Medical Education, 46(2), 201-215. doi:10.1111/j.1365-2923.2011.04137.x.

Koriat, A. (1997). Monitoring one's own knowledge during study: A cue-utilization approach to judgments of learning. Journal of Experimental Psychology-General, 126, 349-370. doi:10.1037/0096-3445.126. 4.349 .

Koriat, A. (2012a). The relationships between monitoring, regulation and performance. Learning and Instruction, 22, 296-298. doi:10.1016/j.learninstruc.2012.01.002.

Koriat, A. (2012b). The self-consistency model of subjective confidence. Psychological Review, 119, 80-113. doi:10.1037/a0025648.

Krippendorf, K. (2004). Content analysis. An introduction to its methodology. Thousand Oaks, CA: SAGE.

Kurtz, S., Silverman, D., \& Draper, J. (2005). Teaching and learning communication skills in medicine. Oxford: Radcliffe.

Maguire, P., \& Pitceathly, C. (2002). Key communication skills and how to acquire them. British Medical Journal, 325, 697. doi:10.1136/bmj.325.7366.697.

Martin, D., Regehr, G., Hodges, B., \& McNaughton, N. (1998). Using videotaped benchmarks to improve the self-assessment ability of family practice residents. Academic Medicine, 73, 1201-1206.

Mayring, P. (2000). Qualitative content analysis. http://www.qualitative-research.net/index.php/fqs/article/ view/1089/2385. Retrieved 21.10.2014, 2014.

Metcalfe, J., \& Kornell, N. (2005). A region of proximal learning model of study time allocation. Journal of Memory and Language, 52, 463-477. doi:10.1016/j.jml.2004.12.001.

Nelson, T. O., \& Narens, L. (1990). Metamemory: A theoretical framework and new findings. In G. H. Bower (Ed.), The psychology of learning and motivation (Vol. 26, pp. 125-173). New York: Academic Press. 
Peterson, M. C., Holbrook, J. H., Vonhales, D., Smith, N. L., \& Staker, L. V. (1992). Contributions of the history, physical-examination, and laboratory investigation making in medical diagnoses. Western Journal of Medicine, 156, 163-165.

Rosenbaum, M. E., \& Axelson, R. (2013). Curricular disconnects in learning communication skills: What and how students learn about communication during clinical clerkships. Patient Education and Counseling, 91(1), 85-90. doi:10.1016/j.pec.2012.10.011.

Sandelowski, M. (2000). Combining qualitative and quantitative sampling, data collection, and analysis techniques in mixed-method studies. Research in Nursing and Health, 23, 246-255.

Schön, D. A. (1983). The reflective practitioner. How professionals think in action. Aldershot, GB: Ashgate.

Silverman, J., Kurtz, S., \& Draper, J. (2005). Skills for communicating with patients. Oxford: Radcliffe.

Thiede, K. W., \& Anderson, M. C. M. (2003). Summarizing can improve metacomprehension accuracy. Contemporary Educational Psychology, 28(2), 129-160. doi:10.1016/s0361-476x(02)00011-5.

Thiede, K. W., Anderson, M. C. M., \& Therriault, D. (2003). Accuracy of metacognitive monitoring affects learning of texts. Journal of Educational Psychology, 95, 66-73. doi:10.1037/0022-0663.95.1.66.

Thiede, K. W., Dunlosky, J., Griffin, T. D., \& Wiley, J. (2005). Understanding the delayed-keyword effect on metacomprehension accuracy. Journal of Experimental Psychology-Learning Memory and Cognition, 31, 1267-1280. doi:10.1037/0278-7393.31.6.1267.

van Loon, M. H., de Bruin, A. B. H., van Gog, T., \& van Merriënboer, J. J. G. (2013). Activation of inaccurate prior knowledge affects primary-school students' metacognitive judgments and calibration. Learning and Instruction, 24, 15-25. doi:10.1016/j.learninstruc.2012.08.005.

van Merriënboer, J. J. G. (1997). Training complex cognitive skills. Englewood Cliffs, NJ: Educational Technology Publications.

Williams, C., Cantillon, P., \& Cochrane, M. (2001). The doctor-patient relationship: From undergraduate assumptions to pre-registration reality. Medical Education, 35(8), 743-747. doi:10.1046/j.1365-2923. 2001.00978.x.

Wouda, J. C., \& van de Wiel, H. B. M. (2013). Education in patient-physician communication: How to improve effectiveness? Patient Education and Counseling, 90, 46-53. doi:10.1016/j.pec.2012.09.005.

Yedidia, M. J., Gillespie, C. C., Kachur, E., Schwartz, M. D., Ockene, J., Chepaitis, A. E., \& Lipkin, M. (2003). Effect of communications training on medical student performance. Journal of the American Medical Association, 290, 1157-1165.

Zolnierek, K. B. H., \& DiMatteo, M. R. (2009). Physician communication and patient adherence to treatment a meta-analysis. Medical Care, 47, 826-834. 